\title{
Quantitative assessment of strain and heat treatment on twin formation in commercially pure nickel
}

\author{
Q. Li, J. R. Cahoon \& N. L. Richards \\ Department of Mechanical and Manufacturing Engineering, \\ University of Manitoba, Winnipeg, Manitoba, Canada
}

\begin{abstract}
Thermomechanical treatment comprising cold working to $6 \%$ strain followed by annealing at temperatures in the range $700{ }^{\circ} \mathrm{C}$ to $1000{ }^{\circ} \mathrm{C}$ greatly increases the fraction of special boundaries, primarily $\Sigma 3$ type. The accompanying generation of annealing twins is analysed using the accident growth model due to Gleiter and the phenomenological model of Pande et al. It is shown that Gleiter's model, which contains no scaling factors, when used correctly, predicts the twin density in $\mathrm{Cu}$ alloys and pure nickel. The model due to Pande et al also predicts the twin density in Ni but this model incorporates two scaling factors that detract from its generality.
\end{abstract}

Keywords: special grain boundaries, annealing twins, copper alloys, nickel.

\section{Introduction}

It has been long accepted that thermomechanical treatments can alter the size, shape and crystallographic orientation of grains. In 1984, Watanabe [1] proposed that the type of grain boundaries present could also be controlled sand thus the concept of "grain boundary engineering" was initiated. Grain boundary engineering has been used to increase the fraction of "special grain boundaries", usually defined in terms of coincidence lattice site (CSL) boundaries. A high fraction of low $\Sigma$ CSL boundaries $\{\Sigma(\leq 29)\}$ has been shown to improve resistance to intergranular crack propagation in Inconel $600[2,3]$ and to substantially improve the elevated temperature crack growth resistance of a nickel-based superalloy [4]. For type 304 stainless steel and alloy 600, high 
$\Sigma$ CSL boundary fractions resulted in reduced crack growth rates. High special grain boundary fractions also resulted in a significant reduction of intergranular stress corrosion cracking in irradiated type 304 stainless steel [5]. It has been clearly demonstrated that high fractions for $\Sigma$ CSL special boundaries can substantially improve the resistance to creep, fatigue, and environmental degradation of engineering alloys.

The purpose of the present investigation was to increase the fraction of $\Sigma C S L$ special boundaries in commercially pure nickel by employing an appropriate thermomechanical treatment. Following treatment, the fraction of special boundaries was determined using orientation imaging microscopy and the annealing twin density was also determined. The experimental values for annealing twin density are compared to the theoretical models of Gleiter [6] and Pande et al [7].

\section{Experimental}

The material used for this investigation was commercial purity nickel sheet, $3 \mathrm{~mm}$ thick, mill annealed at $750^{\circ} \mathrm{C}$. Work completed by Guyot et al [8] indicated that cold rolling $6 \%$ reduction in area would be a good starting point for the investigation. Therefore, strips of the as-received sheet were cold rolled $6 \%$ reduction in area and annealed for various times at temperatures from $500^{\circ} \mathrm{C}$ to $1000^{\circ} \mathrm{C}$ to obtain a range of grain sizes. Following the anneals, the fraction of special grain boundaries was determined using orientation imaging software EDAX/TSL, version 3.5, on a JEOL 5900 SEM equipped with an ultra thin, Oxford EDS window. Grain sizes and annealing twin densities were determined using the linear intercept method on a Zeiss microscope equipped with a Clemex Vision Image Analysis System. The results from at least 600 intercepts were averaged to obtain the values.

\section{Results and discussion}

The fraction of special boundaries after ten minutes at the annealing temperature is shown in fig 1 . Over $80 \%$ of the special boundaries were of the $\Sigma 3$ type with small fractions of $\Sigma 9, \Sigma 27$ and other types. The effect of annealing time at $700^{\circ} \mathrm{C}$ on the fraction of special boundaries is given in fig 2 which shows that the optimum annealing time at $700^{\circ} \mathrm{C}$ is $2.2 \times 10^{5} \mathrm{~s}$ or about 61 hours $(220,000 \mathrm{~s})$. The maximum $75 \%$ of special boundaries obtained by annealing at $700^{\circ} \mathrm{C}$ for 61 hours is the same as the maximum percentage of $75 \%$ obtained after annealing at $900^{\circ} \mathrm{C}$ for 10 minutes $(600 \mathrm{~s})$. If the formation of special boundaries is diffusion controlled, then the product of Dt, where $\mathrm{D}$ is the diffusion coefficient and $t$ is the annealing time, should be similar for the optimum times at the various annealing temperatures. However, the formation of special boundaries could be controlled by either grain boundary diffusion or lattice diffusion so both cases must be considered. For the grain boundary diffusion coefficients, we use the results of Čermák [9] who obtained $\mathrm{D}_{\mathrm{gb}}=5.1 \times 10^{-15} \mathrm{exp}$ $(-120,000 / \mathrm{RT}) \mathrm{m}^{2} / \mathrm{s}$ where $\mathrm{R}=8.3145 \mathrm{~J} \cdot \mathrm{K}^{-1} \cdot \mathrm{mole}^{-1}$ and $\mathrm{T}$ is the absolute 
temperature. (Actually, Čermák's results were primarily for the grain boundary diffusion of $\mathrm{Co}$ in $\mathrm{Ni}$, but he obtained a few results for the grain boundary diffusion of $\mathrm{Ni}$ in $\mathrm{Ni}$ that were essentially identical to the values for the diffusion of $\mathrm{Co}$ in Ni. Since Co and Ni atoms are very similar, Čermák concluded that the grain boundary diffusion of $\mathrm{Ni}$ in $\mathrm{Ni}$ was similar to that for the grain boundary diffusion of $\mathrm{Co}$ in Ni. Further, Čermák's results agree well with the earlier results of Wazzan [10].)

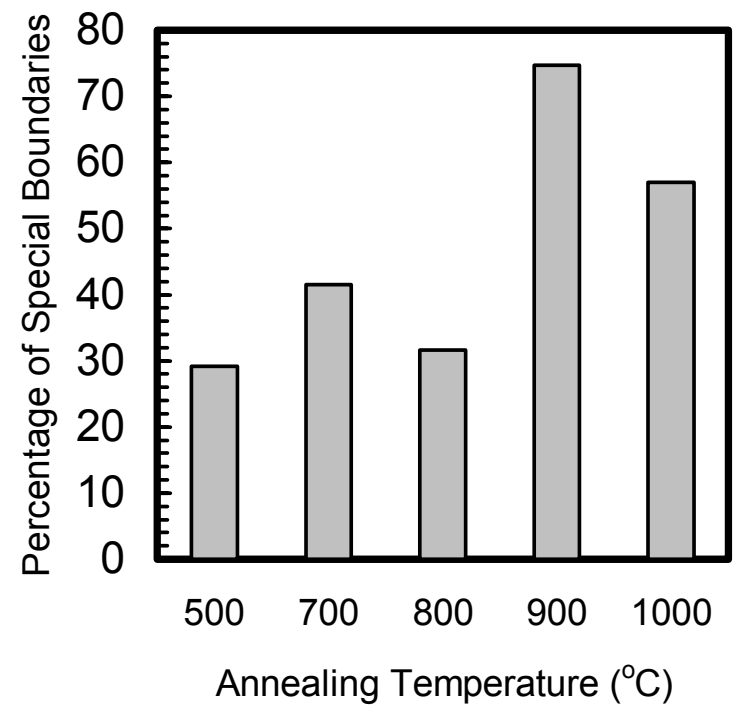

Figure 1: Percentage of special boundaries after cold rolling $6 \%$ reduction in area and annealing for 10 minutes.

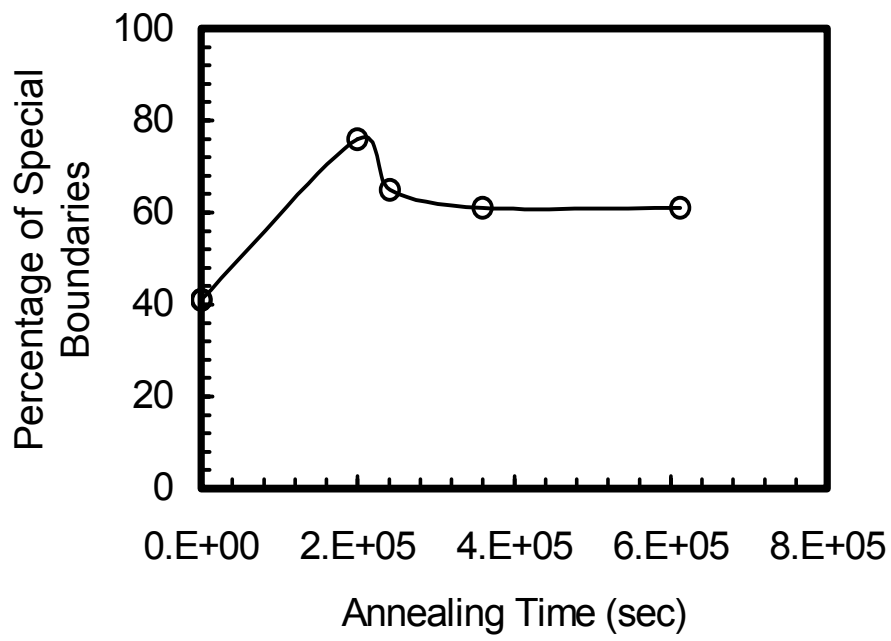

Figure 2: $\quad$ Percentage of special boundaries after cold rolling $6 \%$ reduction in area and annealing at $700^{\circ} \mathrm{C}$. 
For $700^{\circ} \mathrm{C}$, the grain boundary diffusion coefficient is $1.84 \times 10^{-21} \mathrm{~m}^{2} / \mathrm{s}$ and for an annealing time of $220,000 \mathrm{~s}$, the product $\mathrm{Dt}=4.1 \times 10^{-16} \mathrm{~m}^{2}$. For $900^{\circ} \mathrm{C}$, the grain boundary diffusion coefficient is $2.31 \times 10^{-20} \mathrm{~m}^{2} / \mathrm{s}$ and for an annealing time of $600 \mathrm{~s}$, the product $\mathrm{Dt}=1.4 \times 10^{-17} \mathrm{~m}^{2}$. For grain boundary diffusion, the Dt values for the two temperatures differ by a factor of about 40 .

The lattice diffusion coefficient for the diffusion of $\mathrm{Ni}$ in $\mathrm{Ni}$ is given by $\mathrm{D}_{\text {latt }}=1.82 \times 10^{-4} \exp (-285,000 / \mathrm{RT}) \mathrm{m}^{2} / \mathrm{s}[11]$. For $700^{\circ} \mathrm{C}$, the lattice diffusion coefficient is $9.13 \times 10^{-20} \mathrm{~m}^{2} / \mathrm{s}$ and for an annealing time of $220,000 \mathrm{~s}$, the product Dt $=2.0 \times 10^{-14} \mathrm{~m}^{2}$. For $900^{\circ} \mathrm{C}$, the lattice diffusion coefficient is $3.71 \mathrm{X}$ $10^{-17} \mathrm{~m}^{2} / \mathrm{s}$ and for an annealing time of $600 \mathrm{~s}$, the product $\mathrm{Dt}=2.2 \times 10^{-14} \mathrm{~m}^{2}$. For lattice diffusion, the Dt values for the two temperatures are almost identical. Therefore, it appears that the formation of special grain boundaries in commercially pure $\mathrm{Ni}$ is controlled by lattice diffusion.

The annealing twin densities for annealing temperatures of $700^{\circ} \mathrm{C}, 800^{\circ} \mathrm{C}$, and $1000^{\circ} \mathrm{C}$ are plotted versus grain size in figs 3-5 respectively. Two models were used to calculate the theoretical values for the twin density. The first is due to Gleiter [6] who proposed an atomistic model for the formation of annealing twins. Gleiter proposed that the probability, p, of a $\{111\}$ plane being a coherent twin plane is given by:

$$
p=\exp \left\{\sigma_{z}\left(Q-k T \ln \frac{\Delta G^{0}}{k T}\right) /\left[k T \sigma_{z}-\frac{\pi k T \varepsilon^{2} h^{2}}{\left(Q-k T \ln \frac{\Delta G^{0}}{k T}\right)}\right]\right\} .
$$

In eqn (1), $\sigma_{z}$ is the surface energy of a coherent twin boundary, $Q$ is the activation energy for grain boundary migration, $\Delta \mathrm{G}^{0}$ is the difference in the Gibbs' free energy between the growing and the shrinking grain, $h$ is the step height formed by the twin nucleus (taken as the distance between $\{111\}$ planes), $\varepsilon$ is the surface energy of a step of height $h$, and $k$ and $T$ have their usual meanings. The twin density is simply calculated from the product of the number of $\{111\}$ planes per unit length and the probability that any $\{111\}$ is a coherent twin plane. Gleiter, noting that $\mathrm{kT}<<\mathrm{Q}$, deleted the entire term $\mathrm{kT} \ln \left(\Delta \mathrm{G}^{0} / \mathrm{kT}\right)$ from the denominator of eqn (1) (but not the numerator) and obtained a simplified equation. The use of Gleiter's simplified equation usually results in a temperature dependence as well as a grain size dependence for the twin density. Several investigators [7, 12-15] have obtained experimental results (or have proposed) that the twin density is essentially independent of temperature and have therefore considered Gleiter's theory as incorrect. However, Li et al [15] showed that the entire term $\left\{\mathrm{kTln}\left(\Delta \mathrm{G}^{0} / \mathrm{kT}\right)\right\}$ is in fact not negligible and should not be removed from the denominator of eqn (1). Li et al also showed that when Gleiter's complete equation is used, the twinning probability in $\mathrm{Cu}-3 \mathrm{wt} \% \mathrm{Al}$ alloy with a grain size of $300 \mu \mathrm{m}$ is essentially independent of temperature as shown in fig 6. This is in agreement with the observations of Meyers and McCowan [13] as well as Pande et al [14] who suggested that the twinning probability for $300 \mu \mathrm{m}$ grain size $\mathrm{Cu}-3 \mathrm{wt} \% \mathrm{Al}$ alloy is independent of the annealing temperature with a constant value of $\mathrm{p} \approx 2.75 \times 10^{-5}$ (fig 6). 


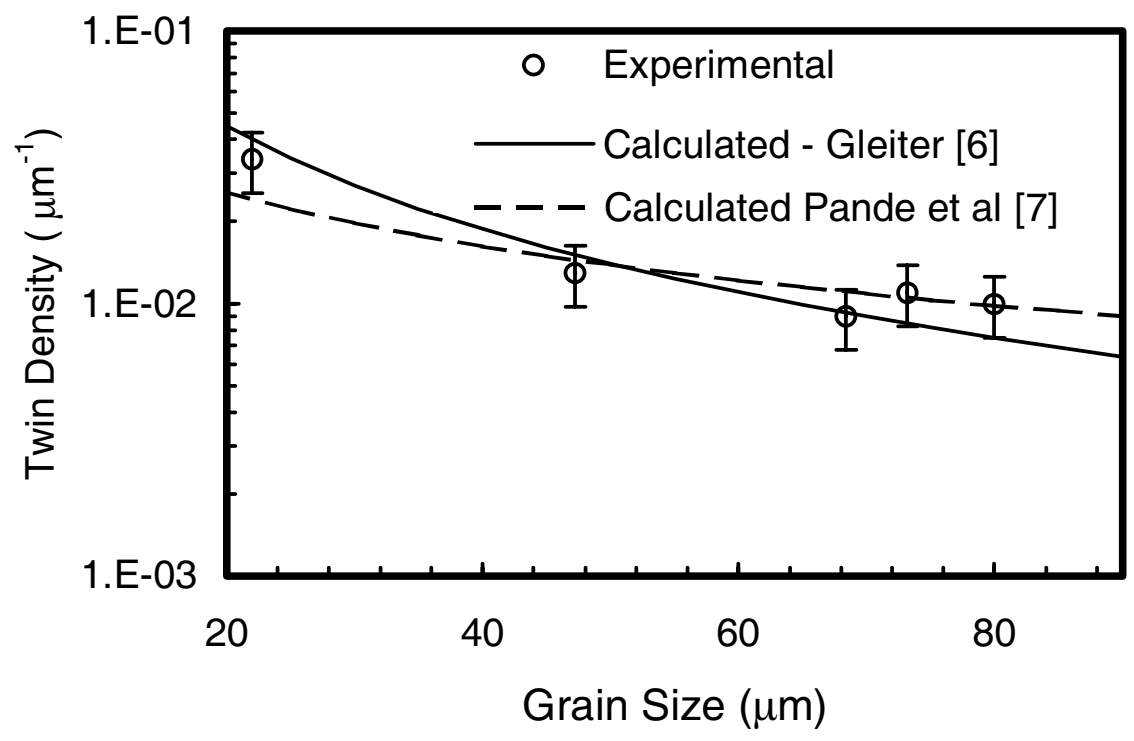

Figure 3: Twinning density for nickel annealed at $700^{\circ} \mathrm{C} .\left(\delta=1.04 \mathrm{~J} / \mathrm{m}^{2}\right.$, $\sigma_{\mathrm{z}}=0.0367 \mathrm{~J} / \mathrm{m}^{2}$ ).

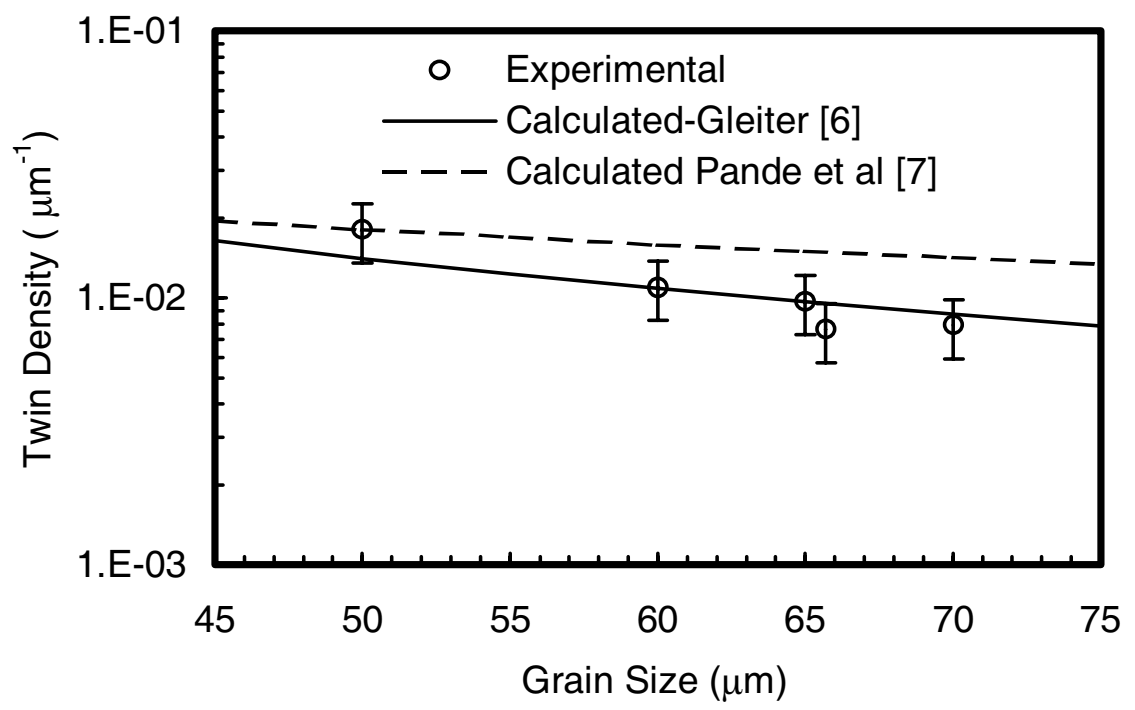

Figure 4: Twinning density for nickel annealed at $800^{\circ} \mathrm{C} .\left(\delta=0.994 \mathrm{~J} / \mathrm{m}^{2}\right.$, $\sigma_{\mathrm{z}}=0.0333 \mathrm{~J} / \mathrm{m}^{2}$ ). 


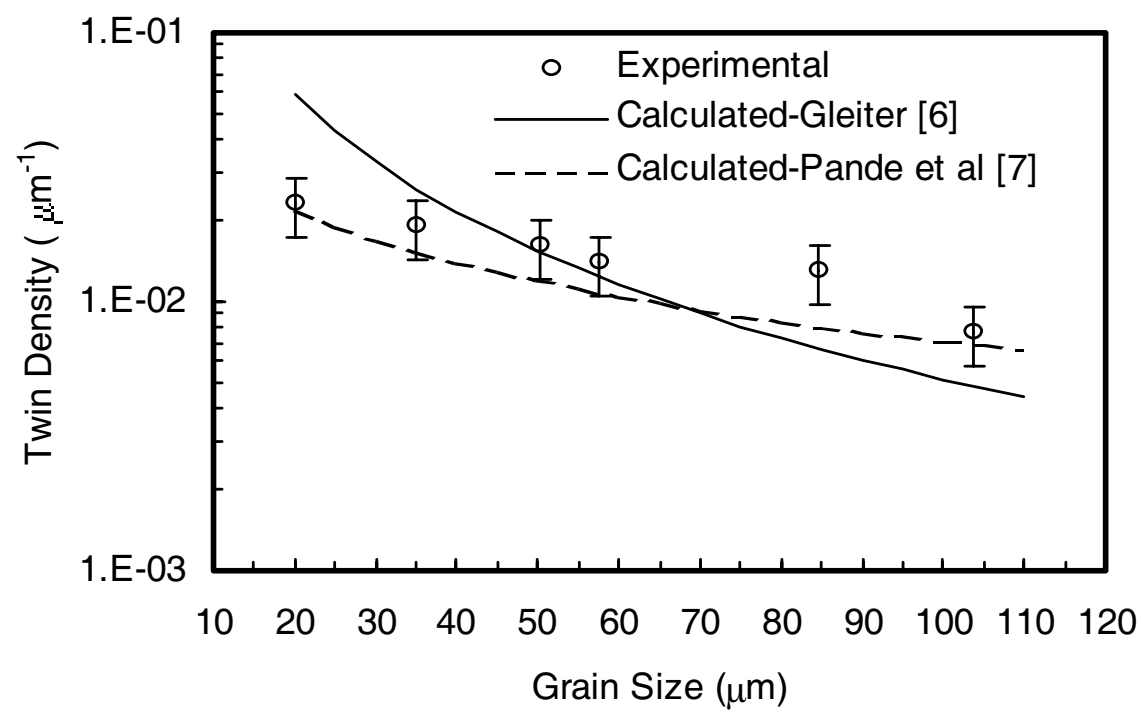

Figure 5: Twinning density for nickel annealed at $1000^{\circ} \mathrm{C} .\left(\delta=0.899 \mathrm{~J} / \mathrm{m}^{2}\right.$, $\sigma_{\mathrm{z}}=0.026 \mathrm{~J} / \mathrm{m}^{2}$ ).

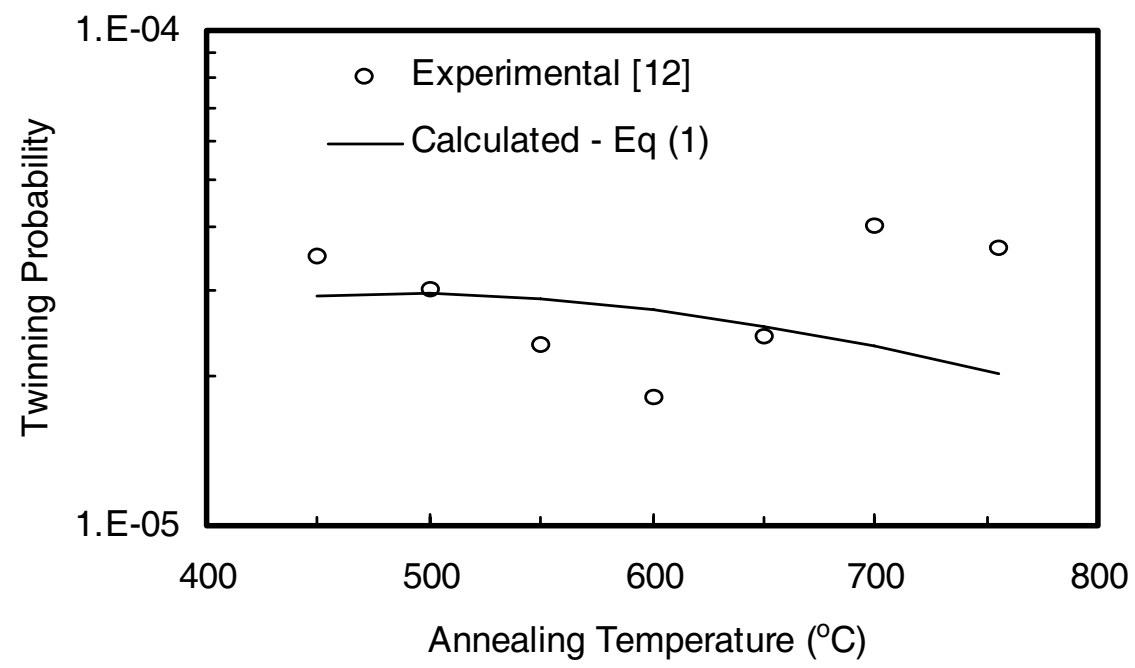

Figure 6: Comparison of experimental values of twinning probability with values calculated from Gleiter's theory, eqn (1), for a grain size $\mathrm{d}=300 \mu \mathrm{m} .\left(\sigma_{\mathrm{z}}=0.01037 \mathrm{~J} / \mathrm{m}^{2}, \mathrm{Q}=1.9 \times 10^{-19} \mathrm{~J} /\right.$ atom, $\delta=0.6 \mathrm{~J} / \mathrm{m}^{2}$, $\mathrm{h}=2.097 \times 10^{-10} \mathrm{~m}, \varepsilon=\delta / 2=0.3 \mathrm{~J} / \mathrm{m}^{2}, \Delta \mathrm{G}^{0}=4 \delta / \mathrm{d}=8 \times 10^{3} \mathrm{~J} / \mathrm{m}^{3}=$ $9.58 \times 10^{-26} \mathrm{~J} /$ atom). 
Assuming that the annealing twin density is independent of annealing temperature, Pande et al $[7,14]$ developed a phenomenological equation giving the probability of a $\{111\}$ plane being a twinning plane as:

$$
p=\frac{k \delta}{d} \ln \left(\frac{d}{d_{0}}\right)
$$

where $\delta$ is the grain boundary energy, $\mathrm{d}$ is the grain diameter, $\mathrm{d}_{0}$ is a material constant representing the smallest grain size for which twinning can occur, and $\mathrm{k}$ is a scaling factor also dependent upon the material.

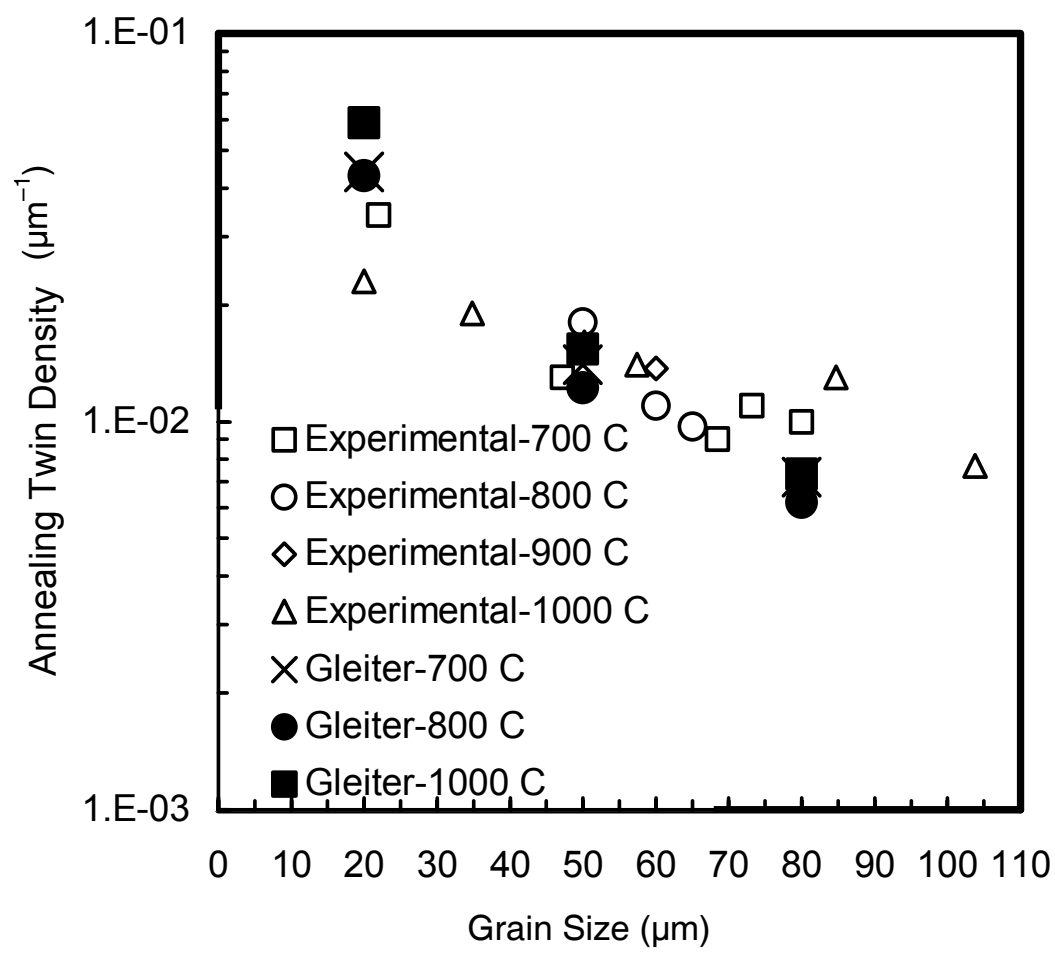

Figure 7: Experimental results for the twin density compared to values calculated from eqn (1) for different grain sizes and annealing temperatures.

The experimental values for the annealing twin densities in commercially pure $\mathrm{Ni}$ are compared with the values calculated from both eqn (1) and eqn (2) in figs 3 to 5 . The values used for the variables in eqn (1) were $Q=120,000 \mathrm{~J} / \mathrm{mole}$ $=2.0 \times 10^{-19} \mathrm{~J} /$ atom and $\mathrm{h}=2.0344 \times 10^{-10} \mathrm{~m}$. The value of the step energy, $\varepsilon$, is taken as $\varepsilon=\delta / 2$ [6] where $\delta$ is the grain boundary energy which varies with temperature and is taken from data given by Murr [16]. The value of $\Delta G^{0}$ is 
taken as $\Delta \mathrm{G}^{0}=4 \delta / \mathrm{d}[6]$ and converted to the appropriate units using the atomic weight and density of pure Ni. Following Gleiter [6], the surface energy of a coherent twin boundary, $\sigma_{z}$, was used as an adjustable parameter to obtain a good fit with the experimental data. The values of twin density calculated from the Gleiter model, eqn (1), are given by the solid lines in figs 3-5.

Pande et al [14] suggested that the constant $\mathrm{d}_{0}$ in eqn (2) should be about $1 \mu \mathrm{m}$ for Ni. Choosing values of $\mathrm{d}_{0}=1.5 \mu \mathrm{m}$ and $\mathrm{k}=1.9 \times 10^{-11} \mathrm{~m}^{3} / \mathrm{J}$ results in reasonable agreement with the experimental values as shown by the dashed lines in figs 3-5. However, the formulation due to Gleiter is more general in that it uses only one adjustable parameter, $\sigma_{z}$, and this is approximately $0.03 \mathrm{~J} / \mathrm{m}$ for the temperature range $700^{\circ} \mathrm{C}-1000^{\circ} \mathrm{C}$. The value of $\sigma_{z}=0.03$ seems reasonable in comparison to the values of $\sigma_{\mathrm{z}}=0.01$ for $\mathrm{Cu}-3 \mathrm{wt} \% \mathrm{Al}$ and $\sigma_{\mathrm{z}}=0.02 \mathrm{~J} / \mathrm{m}^{2}$ for pure $\mathrm{Cu}$ [15]. Further, use of the Gleiter formulation, eqn (1), results in calculated values for the twin density that are essentially independent of temperature even though the formulation explicitly contains the temperature. This is illustrated in fig 7 where the calculated twin density is essentially independent of temperature and agrees well with experimental values.

\section{Conclusions}

1. The percentage of special grain boundaries in commercially pure Ni can be increased from about $30 \%$ in the as received material to about $75 \%$ in material cold rolled $6 \%$ reduction in area and annealed at temperatures from $700^{\circ} \mathrm{C}$ to $1000^{\circ} \mathrm{C}$.

2. The special boundaries are primarily $\Sigma 3$ type.

3. The formation of special grain boundaries in commercially pure Ni appears to be controlled by lattice diffusion.

4, The annealing twin density in commercially pure $\mathrm{Ni}$ is essentially independent of temperature for annealing temperatures from $700^{\circ} \mathrm{C}$ to $1000^{\circ} \mathrm{C}$.

5. Values for the annealing twin density calculated from the Gleiter model and including all terms in the equation, agree well with experimental values.

6. The phenomenological equation due to Pande et al [7, 14], eqn (2), results in calculated values for annealing twin densities that agree well with experimental values using values of $\mathrm{d}_{0}=1.5 \mu \mathrm{m}$ and $\mathrm{k}=1.9 \times 10^{-11} \mathrm{~m}^{3} / \mathrm{J}$.

\section{Acknowledgements}

The authors are grateful for the technical support of John Van Dorp, Mike Boskwick, and Don Mardis. The financial support of NSERC in the form of Discovery grants to two of us (J.R. Cahoon and N.L. Richards) is greatly appreciated. 


\section{References}

[1] Watanabe, T., An approach to grain boundary to grain boundary design for strong and ductile polycrystals. Res. Mech. 11, pp. 47-84, 1984.

[2] Palumbo, G., Lehockey, P. Lin, Erb, U. \& Aust, K.T., Grain boundary engineering for intergranular fracture and creep resistance. Microscopy and Microanalysis, Eds Bailey, G.W., Corbett, J.M., Dimlich, R.V.W., Michael, R. \& Zaluzec, N.J., San Francisco Press: San Francisco, pp. 362363, 1996.

[3] Palumbo, G., Lehockey, P. Lin, Erb, U. \& Aust, K.T., A grain boundary engineering approach to materials reliability, MRS Proceedings of the Symposium on Interfacial Engineering for Optimized Properties, 458, pp. 273-383, 1997.

[4] Gao, Y., Kumar, M., Nalla, R.K. \& Ritchie, R.O., High cycle fatigue of nickel-based superalloy ME3 at ambient and elevated temperatures: Role of grain-boundary engineering, Metall. Mater. Trans. A, 36A, pp. 33253333, 2005.

[5] Was, G.S., Alexandreanu B., Andresen, P. \& Kumar, M., Role of coincident site lattice boundaries in creep, corrosion and stress corrosion cracking, Mat. Res. Soc. Symp. Proc., 819, pp. N2.1.1-N2.1.14, 2004.

[6] Gleiter, H., The formation of annealing twins, Acta Metallurgica, 17, pp.1421-1428, 1969.

[7] Pande, C.S., Imam, M.A. \& Rath, B.B., Study of annealing twins in FCC metals and alloys, Metall. Trans. A, 21A, pp. 2891-2896, 1990.

[8] Guyot, B., Lee, S-L., and Richards N.L., Effect of Small Strain Levels on Special Boundary Distribution in Commercially Pure Nickel, J. of Mat. Eng. \& Performance, 14 (1), pp. 85-90, 2005.

[9] Čermák, J., Grain boundary diffusion of Co-60 in nickel, phys. stat. sol., (a), 117, pp. 387-393, 1990.

[10] Wazzan, A.R., Lattice and grain boundary diffusion in nickel, J. Appl. Phys., 36 (11), pp. 3596-3599, 1965.

[11] Burachynsky, V., \& Cahoon, J.R., A theory for solute impurity diffusion, which considers Engel-Brewer valences, balancing the Fermi energy levels, and differences in zero point energy, Metall. Mater. Trans. A, 28A, pp. 563-582, 1997.

[12] Bäro, G. \& Gleiter, H., The formation of annealing twins, Z. Metallkde, 63, pp. 661-663, 1972.

[13] Meyers, M.A. \& McCowan, C., The formation of annealing twins: overview and new thoughts, Interface migration and control of microstructure, Proc. of an Int. Conf. Symp. held in conjunction with ASM's Metals Congress and TMS/AIME fall meeting, Detroit, MI, USA, Sept. 17-21, 1984, eds. C.S. Pande, D.A. Smith, A.H. King \& J. Walter, ASM, Metals Park, OH,1984, pp. 99-123, 1984.

[14] Pande, C.S., Iman, M.A. \& Rath, B.B., Annealing twins in f.c.c. metals and alloys, ibid, pp. 125-129. 
114 Computational Methods and Experiments in Materials Characterisation III

[15] Li, Q., Cahoon, J.R. \& Richards, N.L., On the calculation of annealing twin density, Scripta Metall., 55, pp. 1155-1158, 2006.

[16] Murr, L.E., Interfacial Phenomena in Metals and Alloys, Addison Wesley Publishing Company, Reading, MA, p.133, 1975. 